Original Article

\title{
Apoptin gene delivery by a PAMAM dendrimer modified with a nuclear localization signal peptide as a gene carrier for brain cancer therapy
}

\author{
Yoonhee Bae ${ }^{1,2}$, Jell Lee ${ }^{3}$, Changwon Kho², Joon Sig Choi ${ }^{3}$, and Jin Han ${ }^{1, *}$ \\ 'Department of Physiology, College of Medicine, Cardiovascular and Metabolic Disease Center, Smart Marine Therapeutics Center, Inje University, Busan \\ 47392, ${ }^{2}$ Division of Applied Medicine, Research Institute for Korea Medicine, School of Korean Medicine, Pusan National University, Busan 50612, ${ }^{3}$ Department \\ of Biochemistry, College of Natural Sciences, Chungnam National University, Daejeon 34134, Korea
}

\section{ARTICLE INFO}

Received April 6, 2021

Revised July 12, 2021

Accepted July 15, 2021

*Correspondence

Jin Han

E-mail: phyhanj@inje.ac.kr

Key Words

Cell death

Dendrimers

Gene delivery system

Glioma
ABSTRACT In this study, we aimed to synthesize PAMAMG3 derivatives (PAMAMG3KRRR and PAMAMG3-HKRRR), using KRRR peptides as a nuclear localization signal and introduced histidine residues into the KRRR-grafted PAMAMG3 for delivering a therapeutic, carcinoma cell-selective apoptosis gene, apoptin into human primary glioma (GBL-14) cells and human dermal fibroblasts. We examined their cytotoxicity and gene expression using luciferase activity and enhanced green fluorescent protein PAMAMG3 derivatives in both cell lines. We treated cells with PAMAMG3 derivative/apoptin complexes and investigated their intracellular distribution using confocal microscopy. The PAMAMG3-KRRR and PAMAMG3-HKRRR dendrimers were found to escape from endolysosomes into the cytosol. The JC-1 assay, glutathione levels, and Annexin V staining results showed that apoptin triggered cell death in GBL-14 cells. Overall, these findings indicated that the PAMAMG3-HKRRR/apoptin complex is a potential candidate for an effective nonviral gene delivery system for brain tumor therapy in vitro.

\section{INTRODUCTION}

Glioblastoma multiforme (GBM) is an aggressive primary brain tumor classified as a grade 4 astrocytic glioma based on its histological and molecular features. GBM displays high genetic heterogeneity, with invasive growth, long-distance migration, and angiogenesis $[1,2]$. It is usually resistant to therapies or treatments such as surgery, radiotherapy, and chemotherapy owing to tumor recurrence via infiltration. The survival time for most patients following diagnosis is only $1.5-2$ years [3,4]. Therefore, new therapeutics with improved clinical diagnosis and treatment of GBM are urgently required. Gene therapy is a promising approach that aims to treat and prevent disease progression by delivering genetic material into the patient's cells [5,6]. In general, gene delivery systems are divided into viral and non-viral vectors. Although viral vectors are widely used for gene delivery owing to their high transfection efficiency and gene expression, their fatal defects include carcinogenesis inducing strong immune response, high cytotoxicity, and insertional mutations $[7,8]$. Therefore, nonviral vectors have overcome the limitations of less immunotoxicity, ease of synthesis, specific tissue targeting, and reduced cytotoxicity despite showing lower transgene expression than viral vectors. The most commonly used nonviral vectors for gene delivery are dendrimers, chitosan, cationic lipids, and inorganic nanoparticles [9-11]. Biopolymer-based gene carriers are currently being used for gene therapy owing to their increased biocompatibility, decreased immunogenicity, and effective transgene expression $[12,13]$.

Polyamidoamine (PAMAM) dendrimers are macromolecular cationic polymers with a flexible structure and globular shape (i) (5) This is an Open Access article distributed under the terms of the Creative Commons Attribution Non-Commercial License, which permits unrestricted non-commercial use, distribution, and reproduction in any medium, provided the original work is properly cited. Copyright @ Korean J Physiol Pharmacol, pISSN 1226-4512, elSSN 2093-3827
Author contributions: Y.B. and J.L. performed the cell-based assay experiments. C.K. and J.S.C. coordinated the study. Y.B. and J.H. prepared the manuscript. J.H. supervised the study. 
depending on dendrimer generation. In particular, PAMAM has been widely studied as a well-known cationic dendrimer for gene/drug delivery, gene therapy, and medical imaging owing to its tunable size, negligible cytotoxicity, water solubility, and nonimmunogenicity that characterize the suitability of vehicles for gene or drug delivery $[14,15]$. Positively charged amino groups on PAMAM condense the phosphate backbone of DNA via electrostatic interactions with their negative charges, the protonated amine group of PAMAM act as a proton buffer, and the polyplexes effectively facilitate cellular uptake through endocytosis $[16,17]$. However, the application of PAMAM in gene delivery systems is limited owing to its cytotoxicity and low transfection efficiency. To overcome these challenges, many studies have attempted surface modification of PAMAM with chemically grafted functionalities such as cell penetrating peptides, cationic moieties, amino acids, and nuclear localization signal (NLS) to improve gene delivery efficiency and reduce cytotoxicity $[18,19]$. In our previous study, KRRR peptide from mouse fibroblast growth factor 3 was conjugated with PAMAM, as a NLS which introduced a higher transfection efficiency than that of PAMAM in mouse fibroblast cells. The PAMAM peptide conjugated with a NLS had increased nuclear localization via the nuclear pore complex (NPC) by active transport indicating the enhanced effectiveness of gene delivery vectors with high gene expression [20]. Recently, we conjugated KRTR to PAMAMG3 to develop a gene delivery carrier, PAMAMG3-KRTR demonstrating higher gene expression than PAMAMG3. KRTR peptide conjugation onto the PAMAMG3 surface condensed the polyplexes with a net positive charge and facilitated DNA entry via the NPC thereby increasing transfection efficiency [21]. The current study aimed to apply a cancer therapeutic strategy using a tumor-specific apoptosis gene, apoptin and a nonviral carrier for the treatment of human glioma-derived GBL-14 cells.

Apoptin is a small protein comprising 121 amino acids including nuclear localization and nuclear export signal peptides. The cancer-specific toxicity of apoptin becomes functional with its subcellular localization. In various cancer cells, apoptin enters the nucleus; however, in non-transformed cells, it is located mainly in the cytoplasm [22,23]. Apoptin-mediated apoptosis is mitochondria-regulated pathway that is independent of death receptors. Tumor-specific phosphorylation of apoptin at Thr 108 via mitogenic cyclin-dependent kinase induces cell death by nuclear trafficking in transformed cells. However, the precise function and mechanisms underlying the anti-cancer activity of apoptin have not been completely elucidated. Apoptin has potential as an antitumor therapeutic agent owing to its tumor cell-specific nuclear delivery. However, its anticancer applications include nonviral gene delivery carriers with small- molecule anticancer agents $[24,25]$.

Here, we aimed to develop PAMAMG3 derivatives (PAMAMG3-KRRR and PAMAMG3-HKRRR) as more efficient apoptin gene delivery carriers with a nonviral gene delivery system for therapeutic applications. We assessed the in vitro cytotoxicity and gene expression of PAMAMG3 derivative/DNA complexes. Furthermore, we evaluated the subcellular trafficking and localization of PAMAMG3 derivatives using confocal microscopy. After the transfer of the apoptin gene using the PAMAMG3 derivatives into GBL-14 cells and human dermal fibroblasts (HDFs), we performed a JC-1 assay, checked glutathione (GSH) levels, and conducted Annexin V staining to examine the anticancer effects of apoptin in the cells. Results demonstrated apoptin gene transfer to effectively suppress cell viability, increase ROS production by oxidative stress, and induce glioma cell apoptosis through mitochondrial membrane permeability. Our study suggested that PAMAMG3-HKRRR/pJDK-apoptin could be a potential treatment for GBM.

\section{METHODS}

\section{Synthesis of PAMAM dendrimers}

PAMAMG3-KRRR was synthesized using the HOBt/HBTU coupling reaction. First, lyophilized PAMAMG3 (10 mg) was dissolved in $2.5 \mathrm{ml}$ of anhydrous DMF solution (80:20, DMF/ DMSO, v/v) and four equivalents of HOBt, HBTU, and FmocHis(trt)-OH, and eight equivalents of DIPEA were added. The synthesis reaction was performed at $25^{\circ} \mathrm{C}$ for $18 \mathrm{~h}$. Then, FmocLys (Boc)-grafted PAMAMG3 was settled in diethyl ether and centrifuged. Subsequently, the supernatant was removed and the precipitated Fmoc-Lys (Boc)-grafted PAMAMG3 was washed with cold diethyl ether and centrifuged again. The wash step of Fmoc-Lys (Boc)-grafted PAMAMG3 was repeated thrice after which it was dried in nitrogen gas and the Fmoc deprotection reaction was performed in $30 \%$ piperidine solution (30:70, piperidine/DMF, v/v) at $25^{\circ} \mathrm{C}$ for $2 \mathrm{~h}$ in the dark. The deprotected Lys (Boc)-grafted PAMAMG3 was precipitated, washed, dried, and dissolved as described above. Four equivalents of HOBt, HBTU, and additional amino acids, and eight equivalents of DIPEA were added to the deprotected Lys (Boc)-grafted PAMAMG3 solution. Synthesis and Fmoc deprotection were performed as described above. The pbf and Boc protection groups of PAMAM derivatives were eliminated using 95\% trifluoroacetic acid solution (95:2.5:2.5, trifluoroacetic acid/triisopropylsilane $/ \mathrm{H}_{2} \mathrm{O}, \mathrm{v} / \mathrm{v}$ ) at $25^{\circ} \mathrm{C}$ for $7 \mathrm{~h}$. Deprotected PAMAMG3-KRRR was precipitated, washed, and dried as described above. The dried PAMAMG3-KRRR was dissolved in water, placed in a dialysis membrane, and dialyzed against distilled water for $18 \mathrm{~h}$. Next, PAMAMG3-KRRR was lyophilized and obtained as a white powder. PAMAM G3-HKRRR was synthesized using the same method used for the synthesis of PAMAMG3-KRRR. The ${ }^{1} \mathrm{H}$ NMR spectra of PAMAMG3-KRRR and PAMAMG3-HKRRR are shown in Fig. $1 B$. 
A
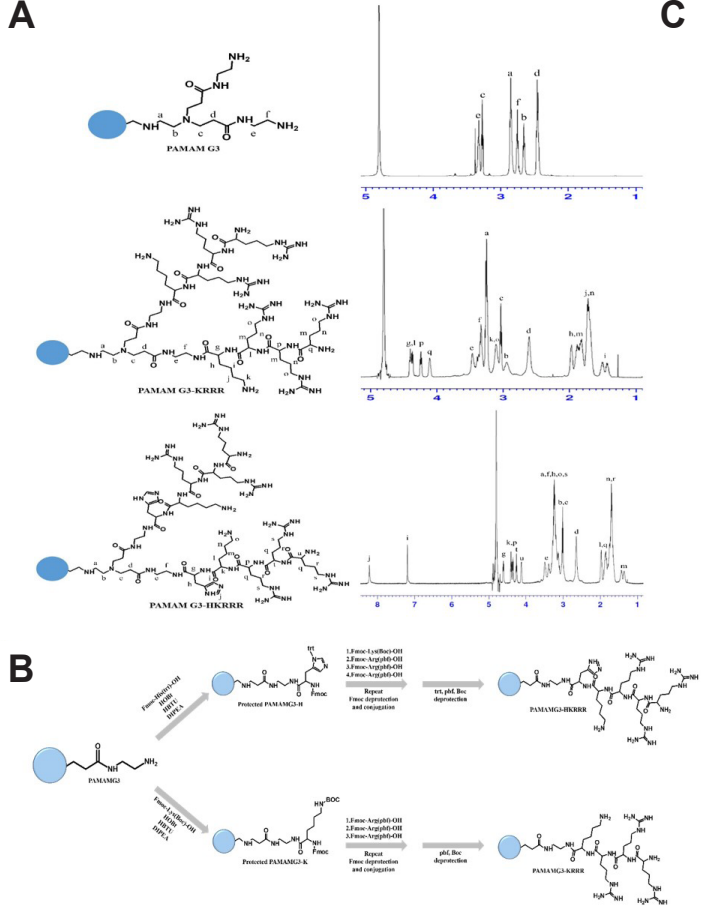

C

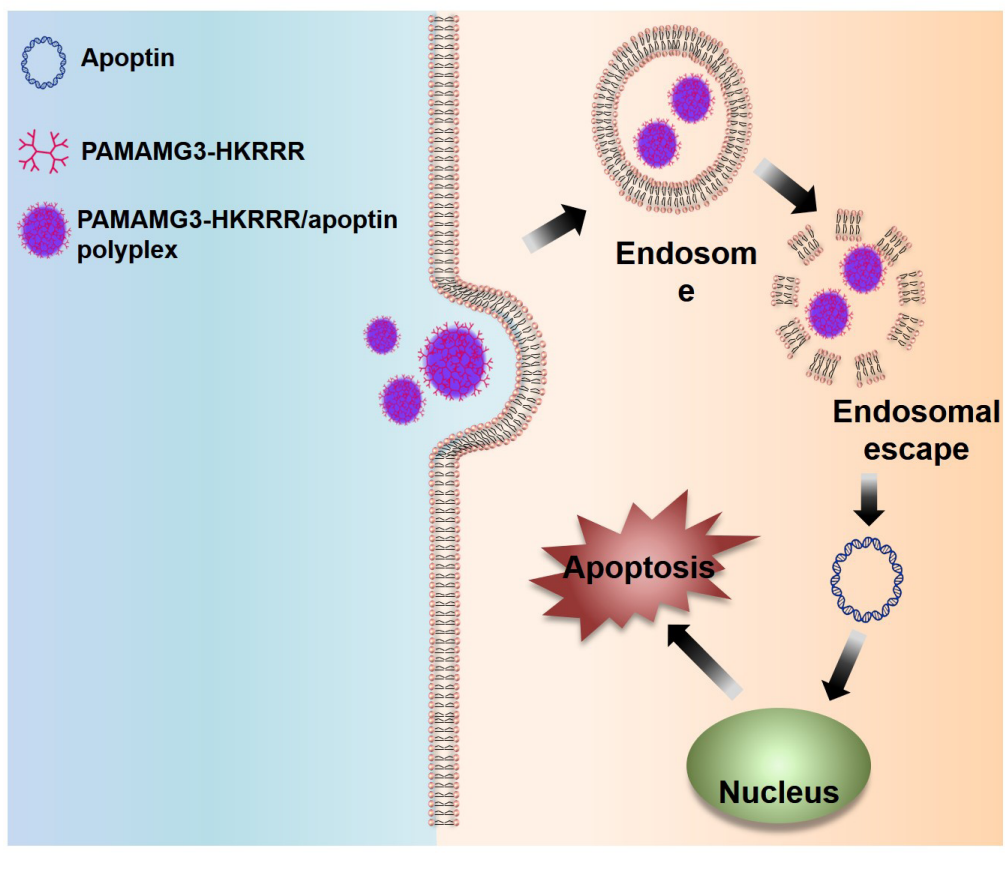

Fig. 1. Synthesis of nonviral gene delivery systems. (A) ' $\mathrm{H}$ NMR spectra of PAMAMG3, PAMAMG3-KRRR, and PAMAMG3-HKRRR. (B) The synthesis scheme of PAMAM derivates conjugated with nuclear localization signal (NLS) peptides. (C) Scheme 1. Diagram of the endocytic pathway and the formation of PAMAMG3-HKRRR/pJDK-apoptin complex and apoptin gene delivery into the nucleus. Apoptin promotes apoptotic cell death of GBL-14 cells.

\section{Plasmids and cell culture}

The plasmids used in this study were provided by An et al. [26]. Human primary glioma (GBL-14) cells and HDFs were cultured in complete DMEM growth medium (Invitrogen, Seoul, Korea).

\section{PicoGreen assay}

Complexes of pJDK or pJDK-apoptin with each polymer were prepared with various weight ratios in HEPES buffer. The PicoGreen assay was performed according to the manufacturer's instructions as described previously [27].

\section{Cytotoxicity assay}

GBL-14 cells and HDFs were seeded $\left(1.3 \times 10^{4}\right.$ cells/well $)$ in a 96-well culture plate. Each polymer-treated cell was further treated with WST-1 reagent for $2 \mathrm{~h}$ at $37^{\circ} \mathrm{C}$. Cell viability was determined using the EZ-Cytox assay kit (DoGen, Seoul, Korea).

Lactate dehydrogenase (LDH) levels were assessed using a $\mathrm{LDH}$ assay kit (DoGen). GBL-14 cells and HDFs were seeded $\left(1.3 \times 10^{4}\right.$ cells/well) in a 96-well culture plate and the LDH degree of each sample was analyzed according to the manufacturer's instructions described previously [27].

\section{Cellular uptake imaging}

GBL-14 cells and HDFs were cultured $\left(5 \times 10^{3}\right.$ cells/well $)$ in 8 -well culture plates (Ibidi, Seoul, Korea). Cells were incubated with the following complexes (Alexa Fluor 546-labeled pJDK or pJDK-apoptin and PAMAMG3, PAMAMG3-KRRR, or PAMAMG3-HKRRR) with a weight ratio of 4 and then incubated for 24 $\mathrm{h}$. The cells were stained with DAPI for $5 \mathrm{~min}$ and images were obtained using a confocal microscope.

\section{In vitro transfection assay}

GBL-14 cells and HDFs were cultured $\left(1.3 \times 10^{4}\right.$ cells/well $)$ in a 96-well culture plate. The complexes (pJDK-Luci $[1 \mu \mathrm{g}]$ and PAMAMG3, PAMAMG3-KRRR, or PAMAMG3-HKRRR) were prepared with various weight ratios in $20 \mu \mathrm{l}$ of FBS-free DMEM medium and then incubated for $30 \mathrm{~min}$ at room temperature. The luciferase activity of each sample was analyzed according to the manufacturer's instructions as described previously [27].

\section{Imaging of intracellular trafficking}

GBL-14 cells and HDFs were cultured $\left(5 \times 10^{3}\right.$ cells/well $)$ in 8 -well culture plates. Cells were incubated with pJDK or pJDKapoptin $(1 \mu \mathrm{g})$ and Alexa Fluor 488-labeled PAMAMG3, PAMAMG3-KRRR, or PAMAMG3-HKRRR with a weight ratio of 4 in 
FBS-free DMEM medium for $24 \mathrm{~h}$ at $37^{\circ} \mathrm{C}$. The cells were treated with LysoTracker (Invitrogen) as acidic lysosomal compartments for $15 \mathrm{~min}$ at $37^{\circ} \mathrm{C}$. The cell nuclei were counterstained with DAPI for $5 \mathrm{~min}$ at $37^{\circ} \mathrm{C}$. Finally, images were obtained using a confocal microscope.

\section{Analysis of mitochondrial membrane potential (MMP)}

GBL-14 cells and HDFs were seeded $\left(1.5 \times 10^{5}\right.$ cells/well $)$ in 6 -well culture plates. Cells were treated with complexes formed under conditions similar to those used in intracellular trafficking experiments and stained with $2 \mu \mathrm{M}$ JC-1 DMEM medium for 15 $\min$ at $37^{\circ} \mathrm{C}$. The fluorescence intensity of each sample was quantitatively measured by flow cytometry.

\section{Measurement of intracellular GSH}

GSH content was determined using a glutathione colorimetric assay (Thermo Fisher Scientific, Waltham, MA, USA). GBL14 cells and HDFs were cultured $\left(1.8 \times 10^{5}\right.$ cells/well $)$ in 6 -well culture plates. The cells were exposed to the complexes for $24 \mathrm{~h}$. GSH levels in each sample were analyzed according to the manufacturer's instructions as described previously [27].

\section{Annexin V staining}

GBL-14 cells and HDFs were seeded $\left(1.8 \times 10^{5}\right.$ cells/well $)$ in 6 -well culture plates. Complex formation was carried out under conditions similar to those described for the intracellular trafficking experiments. Apoptotic events were analyzed via Annexin $\mathrm{V}$ and PI staining following the manufacturer's instructions as described previously in detail [28].

\section{Dynamic light scattering and $\xi$-potential measurements}

The complexes were prepared with a weight ratio of 4 in HEPES buffer and incubated for $30 \mathrm{~min}$ at $25^{\circ} \mathrm{C}$. The hydrodynamic particle size and $\xi$-potential of the samples were measured using an ELS-Z analyzer (Otsuka Electronics Korea, Seoul, Korea) and Zetasizer Nano ZS system (Malvern Panalytical, Seoul, Korea).

\section{Statistical analysis}

All results are shown as mean \pm standard deviation and were analyzed using unpaired Student's t-test. Statistical analyses were performed using GraphPad Prism 8 (GraphPad Software Inc., La Jolla, CA, USA).

\section{RESULTS}

\section{Synthesis of PAMAMG3-KRRR and PAMAMG3-HKRRR}

In the present study, we explored a safe and effective gene therapy method that delivered a tumor-specific gene, in human primary GBL-14 cells using nonviral vector delivery systems, PAMAMG3-KRRR and PAMAMG3-HKRRR. The synthesis of PAMAMG3-KRRR and PAMAMG3-HKRRR (Fig. 1A) was confirmed by ${ }^{1} \mathrm{H}$ NMR spectroscopy (Fig. 1B). The PAMAMG3HKRRR/pJDK-apoptin complex was released via the endolysosome-mediated uptake and escape from the endolysosomes into the cytosol following cellular uptake thereby ensuring nuclear localization of the apoptin gene which in turn promotes cell death. This process is presented in Scheme 1 (Fig. 1C).

\section{Characterization of complexes}

Complexation of cationic PAMAM dendrimers with pDNA via electrostatic interactions is an important factor for safe and efficient nonviral gene delivery [15]. To examine the complexation of PAMAMG3-KRRR and PAMAMG3-HKRRR with DNA, a PicoGreen reagent assay was performed. A weak fluorescence signal from the complexes indicated DNA condensation with the dendrimer (Fig. 2). PAMAMG3/pJDK or pJDK-apoptin did not condense DNA into PAMAMG3 with a weight ratio ranging from 1 to 2 . As the weight ratio increased from 4 to 8 , PAMAMG3/pJDK or pJDK-apoptin showed complexation with PAMAMG3. However, compact DNA complexes showed a weight ratio of 4 for both PAMAMG3-KRRR and PAMAMG3-HKRRR with pJDK or pJDK-apoptin. Additionally, the mean particle size and $\xi$-potential value of each complex were analyzed as shown in Supplementary Table 1. These results suggest that PAMAMG3KRRR and PAMAMG3-HKRRR may be suitable as a complexmediated gene delivery carrier of pDNA in vitro.

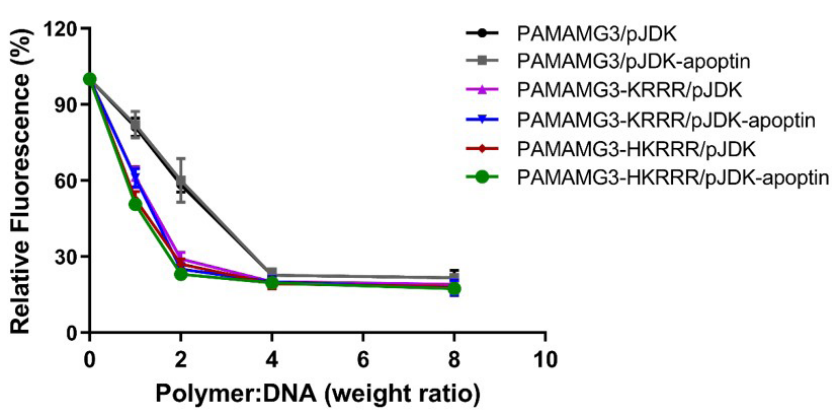

Fig. 2. PicoGreen assays of PAMAMG3 derivative/apoptin complexes. Complexes were prepared using PAMAMG3, PAMAMG3-KRRR, and PAMAMG3-HKRRR with pJDK or pJDK-apoptin at different weight ratios. The fluorescence intensity was normalized to $100 \%$ with pJDK and pJDK-apoptin DNA. Values are expressed as the mean \pm SD of three independent experiments $(n=3)$. 


\section{Cytotoxicity assay}

Cytotoxicity of PAMAMG3, PAMAMG3-KRRR, PAMAMG3HKRRR, and PEI25KD was investigated using the WST-1 assay.
GBL-14 cells and HDFs were treated with different doses of the polymers for 24 and $48 \mathrm{~h}$. PEI25KD showed strong cytotoxicity while PAMAMG3 showed negligible cytotoxicity in both cell types (Fig. 3A-D). Both cell lines treated with PAMAMG3-KRRR

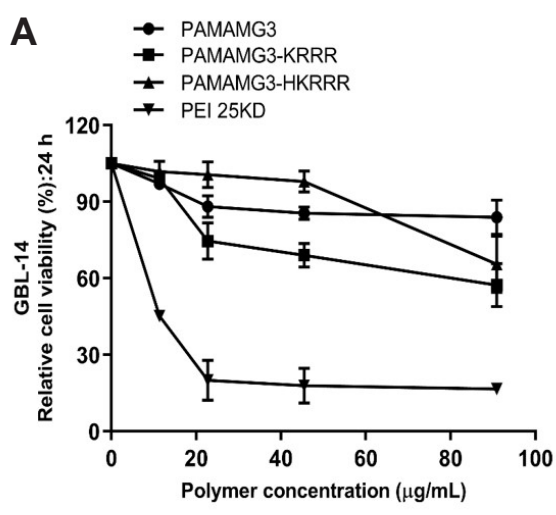

C
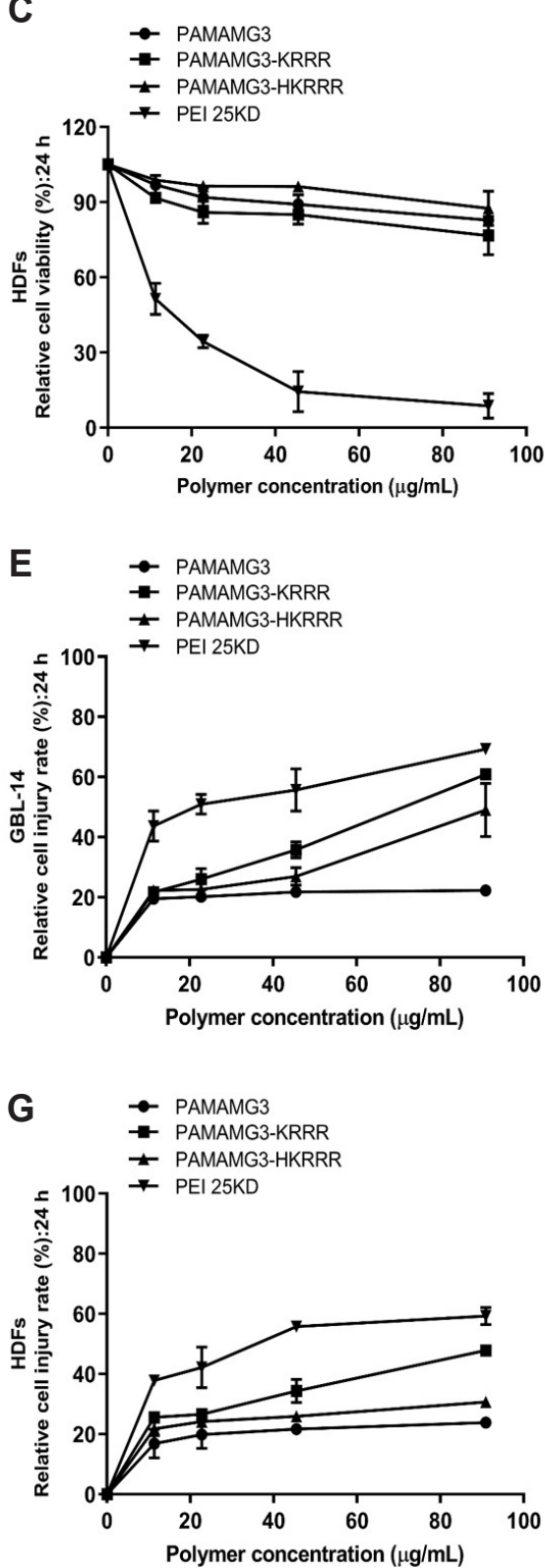

\section{B}

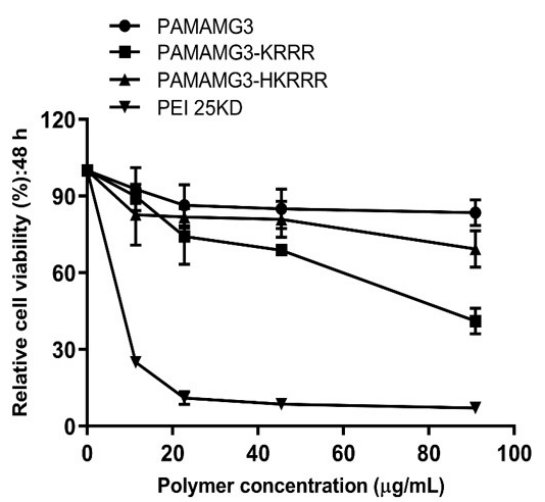

D

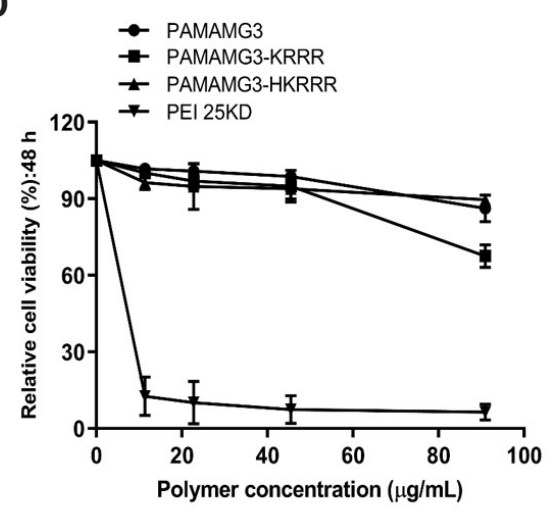

$\mathbf{F}$

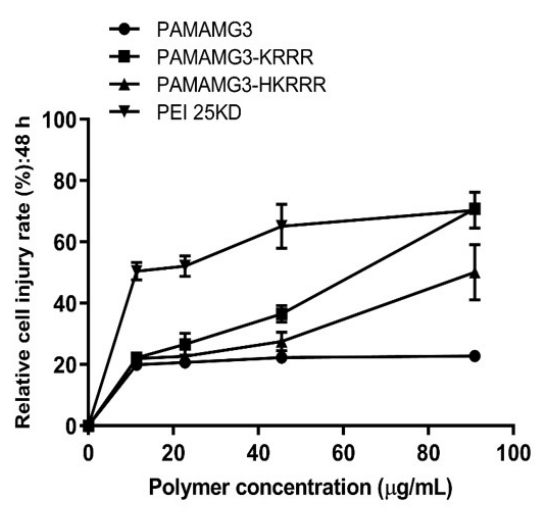

H

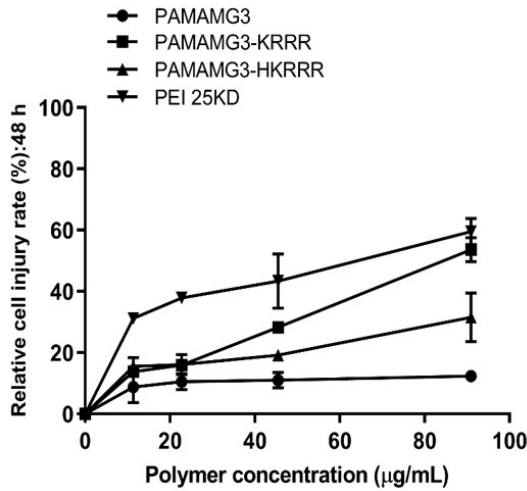

Fig. 3. Cytotoxicity assay of the PAMAMG3 derivatives. (A, B) GBL-14 cells and (C, D) human dermal fibroblasts (HDFs) were exposed to various concentrations of PAMAMG3, PAMAMG3-KRRR, and PAMAMG3-HKRRR. Cytotoxicity was assessed by WST-1 assay after $24 \mathrm{~h}(\mathrm{~A}, \mathrm{C})$ and $48 \mathrm{~h}(\mathrm{~B}, \mathrm{D})$. Values are expressed as the mean $\pm S D$ of three independent experiments $(n=3)$. ( $E, F)$ GBL-14 cells and $(G, H) H D F s$ were incubated under similar condition as in WST-1 assay. Cytotoxicity was assessed using LDH assay after $24 \mathrm{~h}(\mathrm{E}, \mathrm{G})$ and $48 \mathrm{~h}(\mathrm{~F}, \mathrm{H})$. Values are expressed as the mean $\pm \mathrm{SD}$ of three independent experiments $(n=3)$. 
showed high cytotoxicity at $100 \mu \mathrm{g} / \mathrm{ml}$ as the polymer exposure time increased. However, the viability of PAMAMG3-KRRRtreated cells was influenced by both the dose and exposure time. PAMAMG3-HKRRR showed slightly increased toxicity than PAMAMG3-KRRRR when the dose and exposure time increased in both cells. To confirm this metabolic activity, a LDH assay was performed [29]. After 24 and 48 h, PAMAMG3-HKRRR showed lower toxicity in GBL-14 cells and HDFs than PAMAMG3-KRRR when both the dose and exposure time of the polymer were increased (Fig. 3E-H). These results suggest that PAMAMG3HKRRR with increased gene expression may be a potential gene carrier in glioma cells.

\section{Transfection efficiency in vitro}

PAMAM-KRRR had previously shown negligible cytotoxicity and enhanced transfection efficiency as a gene delivery carrier [20]. To examine the gene transfection efficiency of complexes with various weight ratios in both cells, we performed a luciferase assay that expressed the luciferase gene as a $\mathrm{pCN}$-luci reporter gene. The transfection ability of PAMAMG3-KRRR and PAMAMG3-HKRRR was higher than that of PAMAMG3 at increasing polymer doses (Fig. 4A, C). Furthermore, cell cytotoxicity tests were performed for the complexes and the results were similar to those of the luciferase gene experiment. GBL-14 cells and HDFs treated with the polymers remained viable regardless of the polymer doses (Fig. 4B, D). To further investigate the gene expression ability of PAMAMG3-KRRR and PAMAMG3-HKRRR using GFP as a reporter gene, we evaluated the quantitative gene expression using FACS analysis. The expression of the PAMAMG3KRRR/GFP or PAMAMG3-HKRRR/GFP complexes was higher than that of the PAMAMG3/GFP complex (Fig. 5A, B). Interestingly, PAMAMG3-HKRRR-treated GBL-14 cells showed higher gene expression than PAMAMG3-KRRR-treated cells. These results collectively indicate that PAMAMG3-HKRRR is relatively a more efficient gene carrier for glioma cells.

\section{A GBL-14}

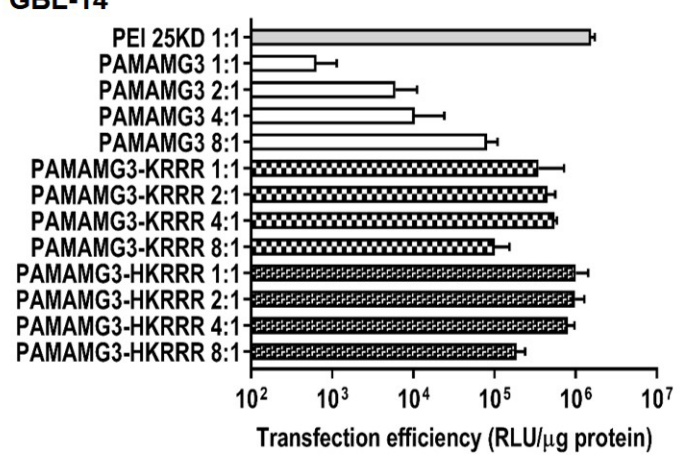

\section{$C_{\text {HDFs }}$}

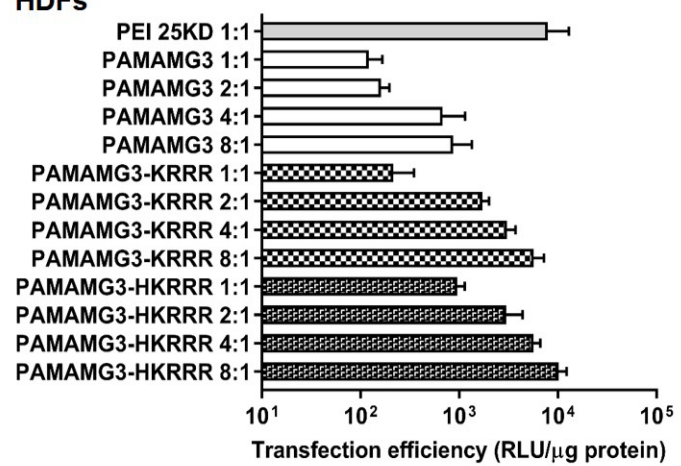

B

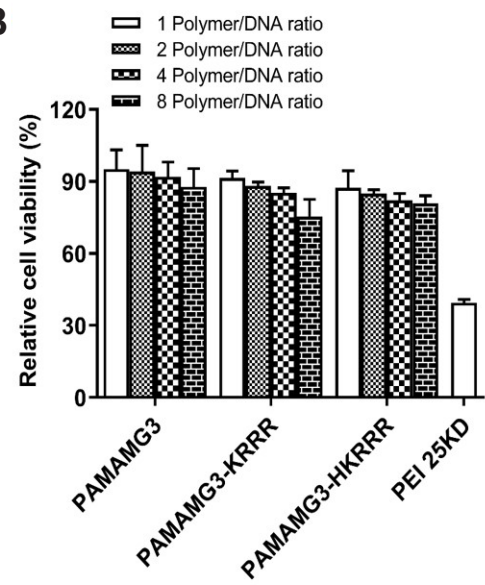

D

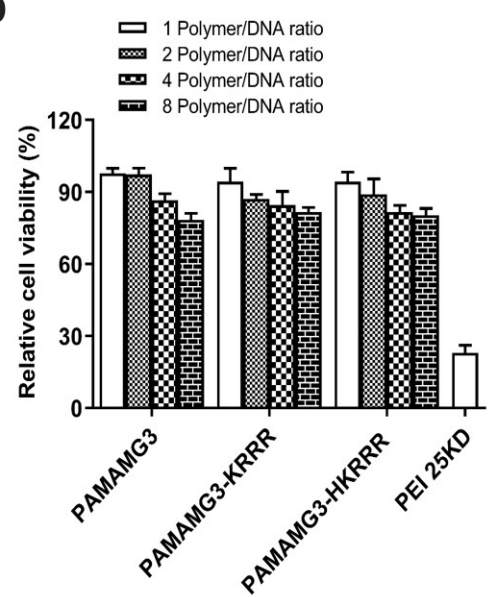

Fig. 4. In vitro transfection efficiency and cell viability of the PAMAMG3 derivatives. (A) GBL-14 cells and (C) human dermal fibroblasts (HDFs) were exposed to PAMAMG3, PAMAMG3-KRRR, and PAMAMG3-HKRRR complexes with pJDK/Luci at different weight ratios for 24 h. (B, D) Cytotoxicity of PAMAMG3 derivative/Luci complexes. Viability of the complexes was assessed using the WST-1 assay. Values are expressed as the mean \pm SD of three independent experiments $(n=3)$. 


\section{A GBL-14}

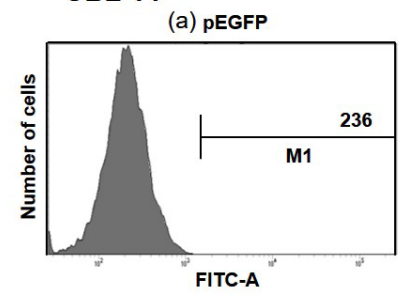

(c) PAMAMG3-KRRR/PEGFP

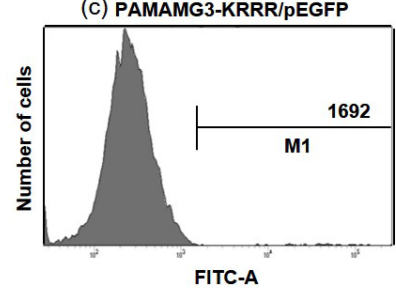

B HDFs

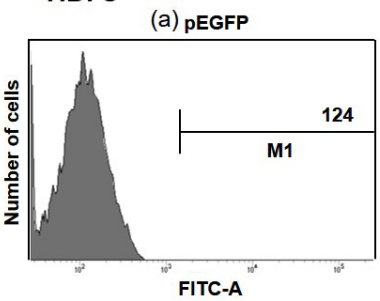

(c) PAMAMG3-KRRR/pEGFP

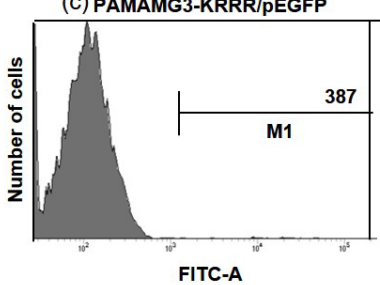

(b) PAMAMG3/pEGFP

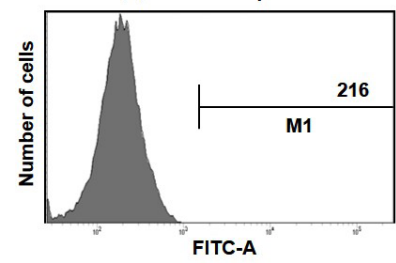

(d) PAMAMG3-HKRRR/PEGFP

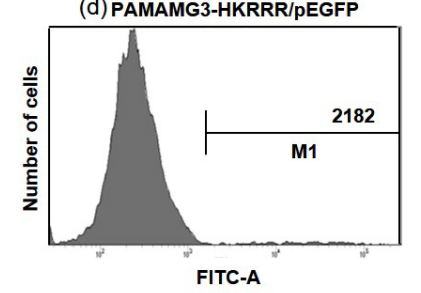

(b) PAMAMG3/pEGFP

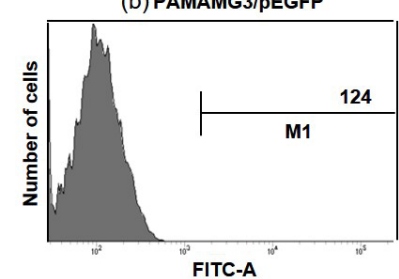

(d) PAMAMG3-HKRRR/pEGFP

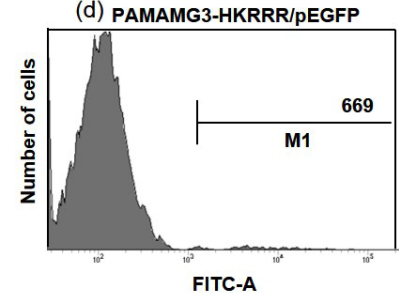

(e) PEI 25KD/pEGFP

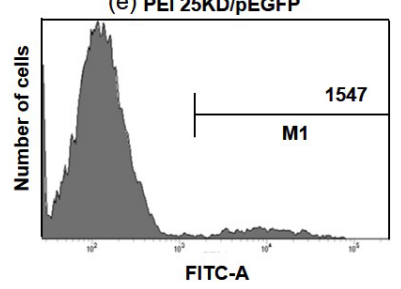

Fig. 5. GFP expression by the PAMAMG3 derivatives. (A) GBL-14 cells and (B) human dermal fibroblasts (HDFs) were exposed to pEGFP, PAMAMG3/pEGFP, PAMAMG3-KRRR/pEGFP, and PAMAMG3HKRRR/pEGFP for $24 \mathrm{~h}$. The cells were harvested, and the cell fluorescence intensity of GFP-positive cells was quantitatively analyzed by flow cytometry. The $x$-axis shows fluorescence intensity and $y$-axis shows number of cells.

\section{Intracellular traffic of complexes}

To evaluate the intracellular uptake ability of the complexes, GBL-14 cells and HDFs were incubated with Alexa Fluor 546-labeled pJDK or pJDK-apoptin and PAMAMG3, PAMAMG3KRRR, and PAMAMG3-HKRRR. pJDK or pJDK-apoptin were observed as red spots in the cytosol and peri-nucleus of both cell types (Fig. 6A, B). Additionally, PAMAMG3-KRRR and PAMAMG3-HKRRR were observed as some red spots inside the nucleus of GBL-14 cells.

To explore intracellular localization after internalization of each complex, we used LysoTracker Red, a cationic fluorescent dye that stains lysosomal membranes under acidic $\mathrm{pH}$ conditions in living cells [30]. Each complex co-localized with LysoTracker (red) and PAMAMG3 and PAMAMG3-KRRR with or without histidine (green) in the cells (Fig. 6C, D). The PAMAMG3HKRRR complex showed increased cytosolic concentrations after its release from the lysosome into the cytosolic compartment likely because of histidine of the imidazole group in PAMAMG3HKRRR which provides a proton buffering effect. The results suggest that PAMAMG3-HKRRR shows considerably higher

gene expression in vitro owing to the increased DNA levels within the nucleus after escaping from the endolysosomes.

\section{Apoptotic effect of the PAMAMG3-HKRRR/pJDK- apoptin complexes in vitro}

To examine whether apoptin induced cell death via the mitochondrial death pathway, we examined the MMP using JC-1, a lipophilic cationic dye that is a hallmark of apoptosis with FACS analysis [31]. The mitochondrial uncoupler, carbonyl cyanide $m$ chlorophenyl hydrazone (CCCP), an inhibitor of oxidative phosphorylation was used as a positive control (Fig. 7A, B). Compared to PAMAMG3-KRRR or PAMAMG3-HKRRR/pJDK (27.2\% and 23.7\%), PAMAMG3-KRRR and PAMAMG3-HKRRR/pJDKapoptin showed depolarization of MMP (33.8\% and 32.4\%) in GBL-14 cells but not in HDFs. This effect suggested that apoptininduced cell damage is associated with the loss of MMP.

The GSH status was examined to validate whether reactive oxygen species generation by oxidative glutamate damage induces mitochondrial depolarization by apoptin, GSH, an intracellular thiol that plays an essential role in antioxidant activity and re- 

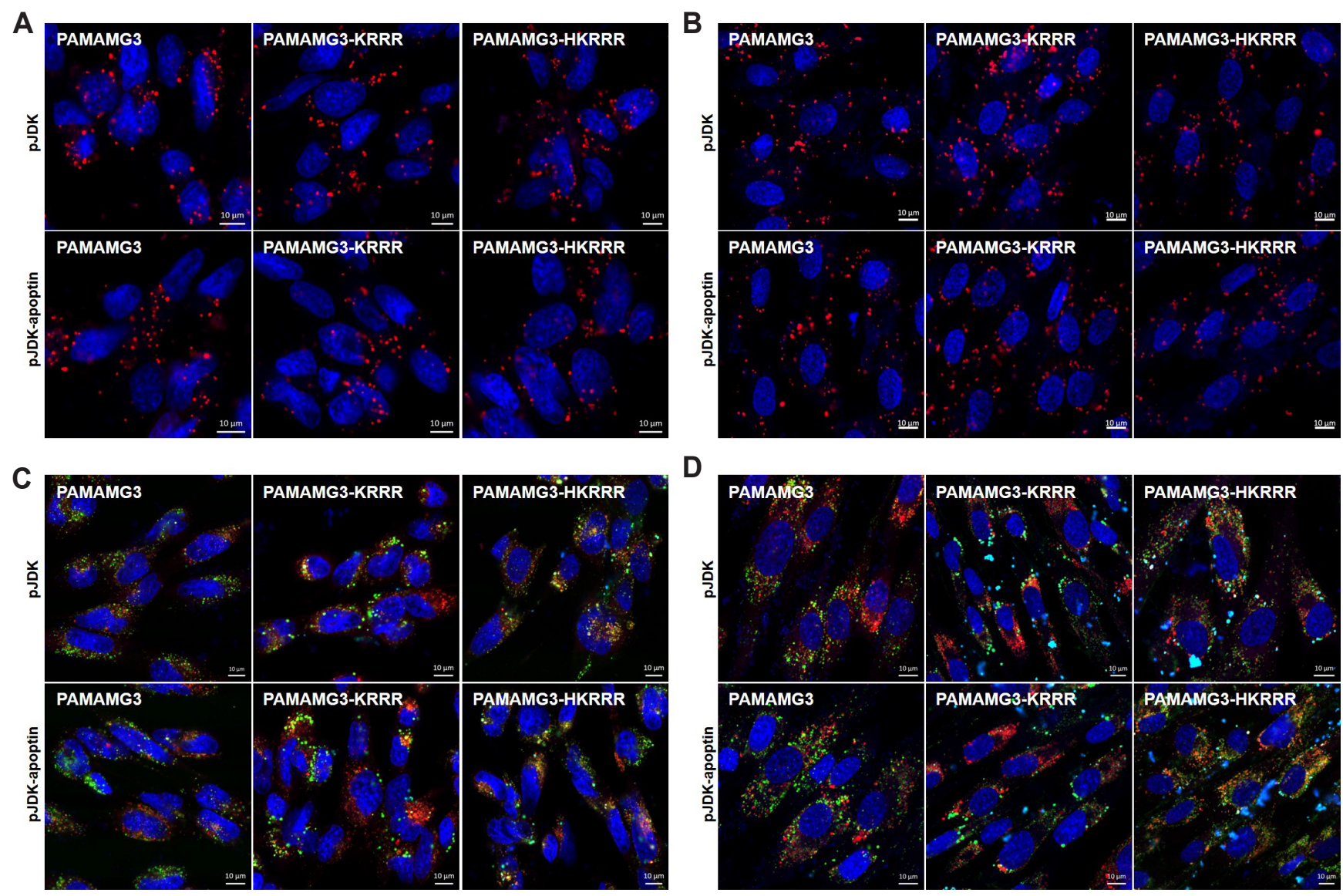

Fig. 6. Uptake and intracellular localization of the PAMAMG3 derivatives. (A) GBL-14 cells and (B) human dermal fibroblasts (HDFs) were treated with PAMAMG3, PAMAMG3-KRRR, and PAMAMG3-HKRRR labeled with Alexa Fluor 546 and pJDK or pJDK-apoptin at the ratio of 4:1 for $24 \mathrm{~h}$. After $24 \mathrm{~h}$ post-exposure, the images were obtained by confocal microscopy. Red fluorescence indicated DNA-labeled with Alexa Fluor 546 dye and blue fluorescence indicated nuclei stained with DAPI. (C, D) Each cell was exposed to Alexa Fluor 488-labeled PAMAMG3, PAMAMG3-KRRR, and PAMAMG3-HKRRR with pJDK or pJDK-apoptin at the ratio of 4:1 for $24 \mathrm{~h}$. After $24 \mathrm{~h}$ post-exposed, the cells were harvested. The live cells were stained with LysoTracker Red for lysosomes and counterstained with DAPI for nuclei.

dox homeostasis against oxidative stress and cytotoxic agents is known to induce apoptosis [32]. Apoptin induced lower GSH levels in GBL-14 cells whereas PAMAMG3-KRRR or PAMAMG3HKRRR-apoptin induced higher GSH levels in GBL-14 cells than PAMAMG3-apoptin (Fig. 7C, D). However cellular GSH levels did not change in the HDFs. These results suggest that cell death induced by PAMAMG3-KRRR with or without histidine and pJDK-apoptin occurs via mitochondrial membrane depolarization which triggers mitochondrion-regulated cell death in glioma cells.

Cell viability owing to pJDK or pJDK-apoptin with PAMAMG3, PAMAMG3-KRRR, and PAMAMG3-HKRRR was checked by performing an EZ-cytotoxicity assay using EZ-Cytox agent. The viability of GBL-14 cells treated with PAMAMG3KRRR with or without histidine and pJDK-apoptin treatment was significantly reduced compared with that of PAMAMG3KRRR with or without histidine and pJDK treatment (Fig. 8A, B). In contrast, each complex used in the assays showed little toxicity and no statistically significant difference between the polymer and polyplex-treated HDFs (Fig. 8C, D).

To further confirm whether PAMAMG3-HKRRR/pJDKapoptin induced apoptosis, the FITC-Annexin V/PI apoptosis assay was performed. PAMAMG3-KRRR or PAMAMG3-HKRRRapoptin-treated cells showed a late apoptotic stage (5.2\% and 9.4\%, respectively) compared with that in PAMAMG3-KRRR or PAMAMG3-HKRRR pJDK-treated cells $(2.0 \%$ and $1.9 \%$, respectively) (Fig. 9A, B). PAMAMG3-HKRRR/pJDK-apoptintreated GBL-14 cells showed early apoptosis (6.8\%) compared with PAMAMG3-HKRRR/pJDK-treated cells (1.5\%). In contrast, apoptosis was not observed in HDFs after treatment with any complex used in the assay. These results suggest that surface modification of low-generation PAMAMG3 dendrimers in polymer-based gene delivery systems such as PAMAMG3-HKRRR generates an efficient carrier for therapeutic gene delivery to the target site of GBL-14 cells. 


\section{A GBL-14}

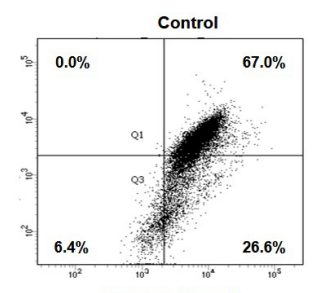

PAMAMG $3 /$ JJDK

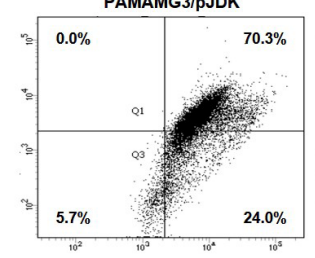

PAMAMG3-KRRR/PJDK
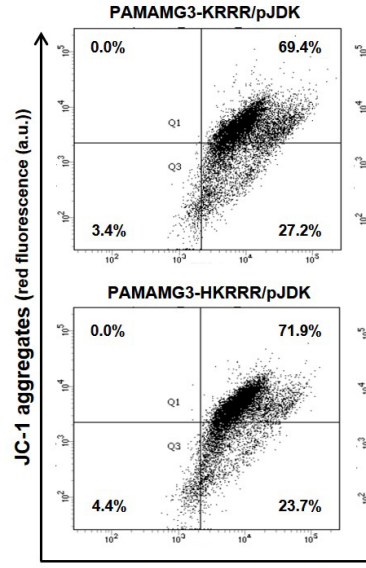

JC-1 monomer green fluorescence (a.u.)
B HDFs
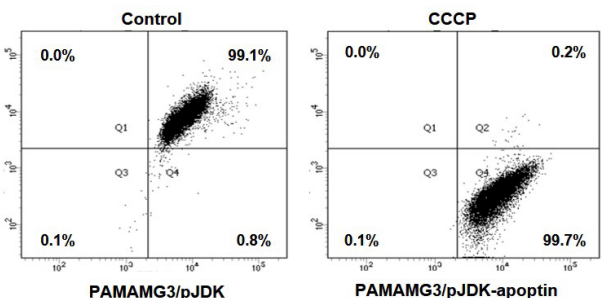

PAMAMG3/pJDK-apoptin

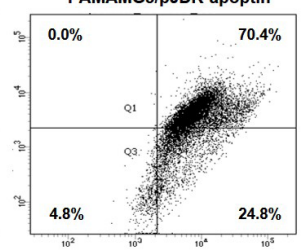

PAMAMG3-KRRR/pJDK-apoptin
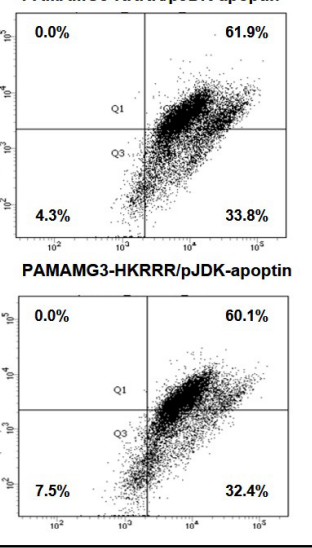

${ }_{10^{5}}$

$\longrightarrow$

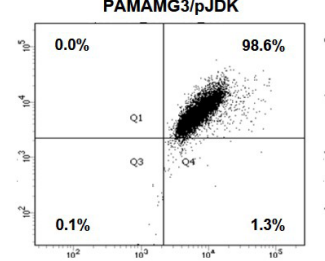

PAMAMG3-KRRR/pJDK
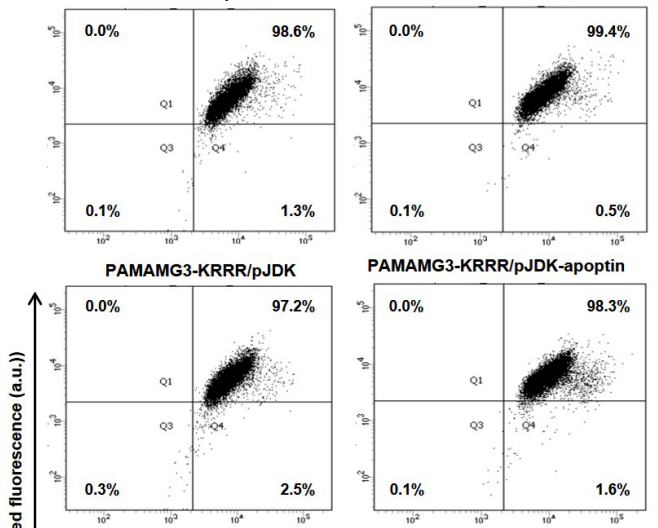

PAMAMG3-KRRR/pJDK-apoptin

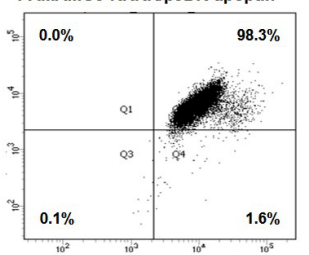

PAMAMG3-HKRRR/pJDK-apoptin

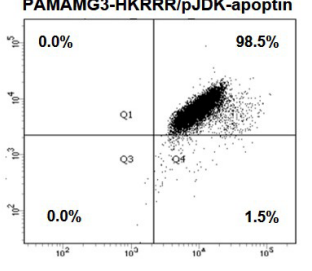

JC-1 monomer green fluorescence (a.u.)

\section{C}
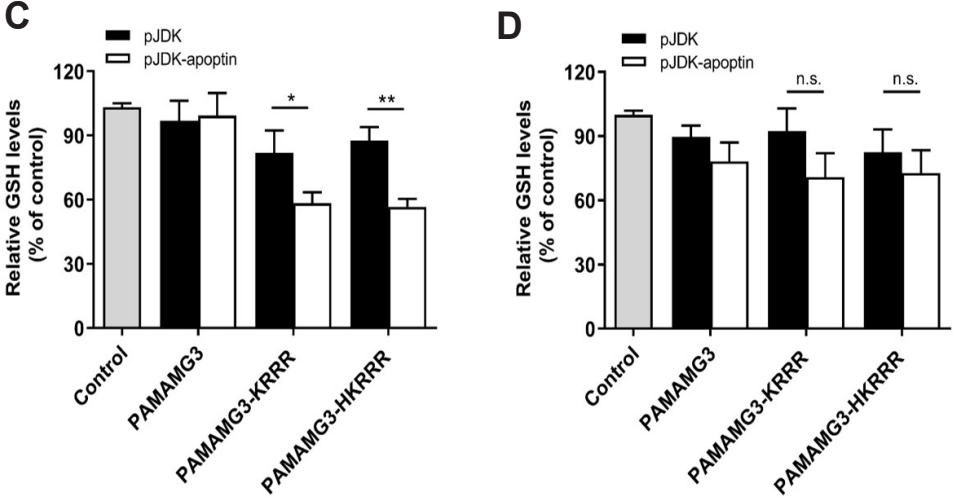

Fig. 7. Mitochondrial membrane depolarization and ROS levels induced by PAMAMG3 derivative/pJDK-apoptin. (A) GBL-14 cells and (B) human dermal fibroblasts (HDFs) were exposed to PAMAMG3, PAMAMG3-KRRR, and PAMAMG3-HKRRR with pJDK or pJDK-apoptin for $24 \mathrm{~h}$. The cells were analyzed for mitochondrial membrane potential (MMP) using flow cytometry after JC-1 staining. The number in the bottom right quadrant indicates the percentage of MMP loss. (C, D) Each cell was exposed to similar conditions as those in panel (A). After $24 \mathrm{~h}$ post-exposure, intracellular ROS levels were assessed using GSH assay as descried in methods. Values are indicted as the mean \pm SD of three independent experiments $(n=3)$. Statistical analyses were conducted using the unpaired two-tailed Students t-test. Asterisks indicate statistically significant values $\left({ }^{* *} p<0.01,{ }^{*} p<0.1\right.$, and not significant [n.s.] [p > 0.05]).

\section{DISCUSSION}

The PAMAMG4-KRRR dendrimer showed enhanced transfection efficiency over PAMAMG4 owing to surface modification with oligopeptides [20]. In this study, we developed PAMAMG3 derivatives (PAMAMG3-KRRR and PAMAMG3-HKRRR) conjugated with KRRR and HKRRR peptides on the surface of PAMAMG3 carrying with the apoptin gene as dendrimer-based gene delivery systems. Cationic polymers with primary amine groups showed cytotoxicity related to cell type, generation, surface 

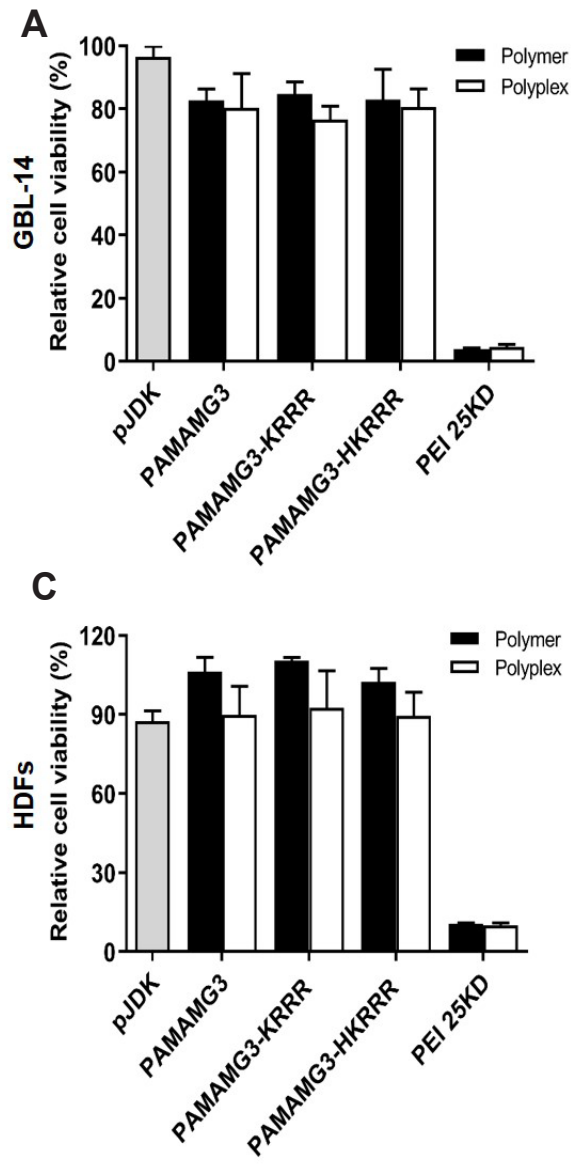

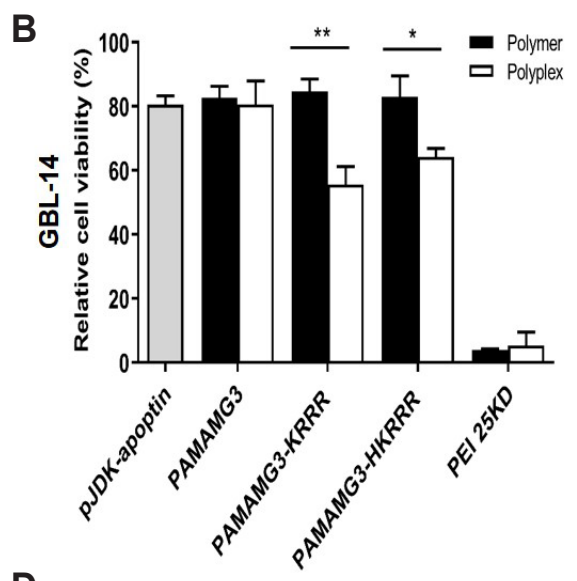

D

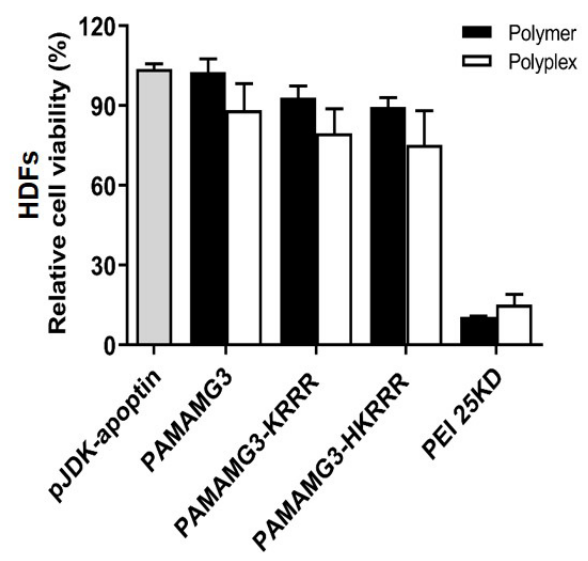

Fig. 8. Cytotoxicity of the PAMAMG3 derivative/apoptin complexes. $(A, B)$ GBL-14 cells and (C, D) human dermal fibroblasts (HDFs) were incubated with PAMAMG3, PAMAMG3-KRRR, and PAMAMG3-HKRRR with pJDK or pJDK-apoptin for $24 \mathrm{~h}$. After $24 \mathrm{~h}$ post-exposure, cytotoxicity of each polymer and polyplex was determined using the WST-1 assay. Values are expressed as mean \pm SD of three independent experiments $(\mathrm{n}=$ 3). Statistical analyses were conducted using the unpaired two-tailed Students t-test. Asterisks indicate statistically significant values $\left({ }^{* *} p<0.01,{ }^{*} p<0.1\right.$, and not significant [n.s.] [p $>0.05])$. charge density, and exposure time [17,33]. However, PAMAMG3 conjugated with the KRRR peptide via histidine (PAMAMG3HKRRR) showed lower cytotoxicity than PAMAMG3-KRRR in GBL-14 cells and HDFs. Compared to PAMAMG3, PAMAMG3KRRR and PAMAMG3-HKRRR showed enhanced gene expression in both cell lines compared to PAMAMG3 depending on the dendrimer weight ratios. Both cell lines treated with complexes formed using PAMAMG3-KRRR and PAMAMG3-HKRRR with plasmid DNA showed negligible cytotoxicity regardless of dendrimer concentration (Fig. 3), indicating that PAMAMG3HKRRR showing an increased gene expression may be a potential gene carrier in glioma cells. The PAMAMG3 derivatives effectively delivered pJDK or pJDK-apoptin into the peri-nucleus and were released from the endolysosomes into the cytosol. This effect was probably owing to the KRRR peptide which is a NLS peptide that passes through the nuclear pore and promotes NLSregulated DNA entry into the nucleus. The results suggested that PAMAMG3-HKRRR showed considerably higher gene expression in vitro owing to the increased DNA access within the nucleus after escape from the endosomelysosomes. Apoptin induces mitochondria- regulated apoptosis in tumor cells without affecting normal cells following different subcellular localizations [22]. Mitochondria-regulated cell death was observed in GBL-14 cells after overexpression of PAMAMG3-HKRRR/pJDK-apoptin rath- er than PAMAMG3-KRRR/pJDK-apoptin (Fig. 7C, D). Therefore, we suggest that PAMAMG3-HKRRR is an effective gene delivery carrier owing to its complete condensation of pDNA and increased gene expression compared with that by PAMAMG3 in both cell lines. NLS peptide sequences bind to the NPC and enhance gene expression by improving DNA entry into the nucleus with a sufficient positive charge because of their sequences rich in basic amino acids such as arginine and lysine [34,35]. Therefore, PAMAMG3-HKRRR/pJDK-apoptin needs to be studied further for the development of a gene therapy approach that is optimal for brain therapy by using nonviral systems. Our results provide a basis for the substantial preclinical application of PAMAMG3HKRRR in brain disease therapy in vivo.

\section{ACKNOWLEDGEMENTS}

This research was supported by the Basic Research Lab Program and the Basic Science Research Program through the National Research Foundation of Korea (NRF) funded by the Korean government Ministry of Science and ICT (NRF2020R1A4A1018943, 2018R1A2A3074998 and 2019R1I1A1A01061429). 
A GBL-14
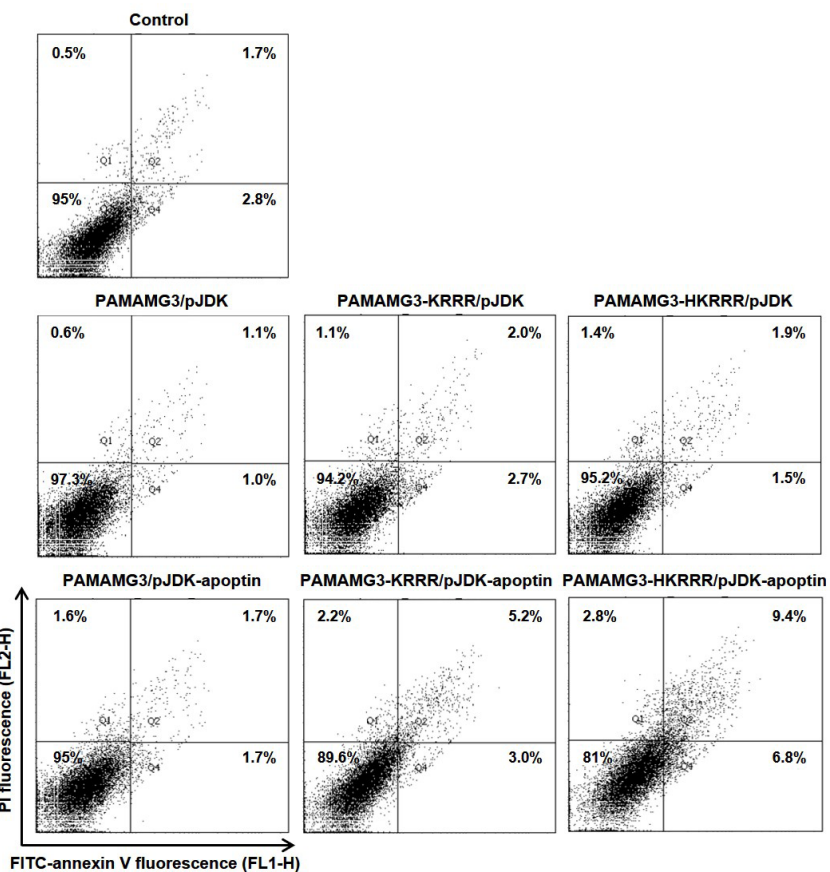

B
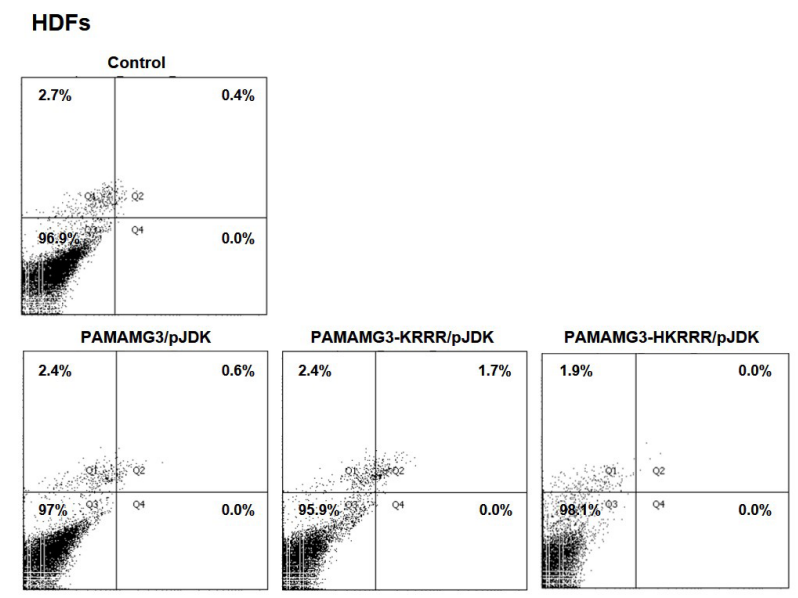

PAMAMG3/pJDK-apoptin PAMAMG3-KRRR/pJDK-apoptin PAMAMG3-HKRRR/pJDK-apoptin

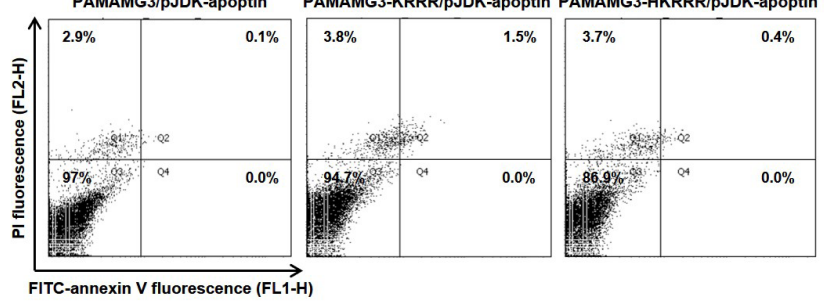

Fig. 9. Apoptosis induced the PAMAMG3 derivative/pJDK-apoptin. (A, B) Annexin V staining of PAMAMG3 derivative/pJDK-apoptin using flow cytometry. GBL-14 cells and human dermal fibroblasts (HDFs) were incubated with PAMAMG3, PAMAMG3-KRRR, and PAMAMG3-HKRRR with pJDK and pJDK-apoptin. After $24 \mathrm{~h}$ post-exposure, apoptosis levels for each polyplex were assessed by flow cytometry. Representative histograms showing four quadrants (Q1: percentage of necrosis, Q2: percentage of late apoptosis, Q3: percentage of live cells, and Q4: percentage of early apoptosis).

\section{CONFLICTS OF INTEREST}

The authors declare no conflicts of interest.

\section{SUPPLEMENTARY MATERIALS}

Supplementary data including one table can be found with this article online at https://doi.org/10.4196/kjpp.2021.25.5.467.

\section{REFERENCES}

1. Zeng W, Tang Z, Li Y, Yin G, Liu Z, Gao J, Chen Y, Chen F. Patientderived xenografts of different grade gliomas retain the heterogeneous histological and genetic features of human gliomas. Cancer Cell Int. 2020;20:1.

2. Assi H, Candolfi M, Baker G, Mineharu Y, Lowenstein PR, Castro MG. Gene therapy for brain tumors: basic developments and clinical implementation. Neurosci Lett. 2012;527:71-77.

3. Reardon DA, Wen PY. Therapeutic advances in the treatment of glioblastoma: rationale and potential role of targeted agents. Oncologist. 2006;11:152-164.

4. Taylor OG, Brzozowski JS, Skelding KA. Glioblastoma multiforme: an overview of emerging therapeutic targets. Front Oncol. 2019;9:963.

5. Pourgholi F, Hajivalili M, Farhad JN, Kafil HS, Yousefi M. Nanoparticles: novel vehicles in treatment of glioblastoma. Biomed Pharma- cother. 2016;77:98-107.

6. Lin G, Zhang H, Huang L. Smart polymeric nanoparticles for cancer gene delivery. Mol Pharm. 2015;12:314-321.

7. Balakrishnan B, David E. Biopolymers augment viral vectors based gene delivery. J Biosci. 2019;44:84.

8. Dunbar CE, High KA, Joung JK, Kohn DB, Ozawa K, Sadelain M. Gene therapy comes of age. Science. 2018;359:eaan4672.

9. Ramamoorth M, Narvekar A. Non viral vectors in gene therapy- an overview. J Clin Diagn Res. 2015;9:GE01-GE06.

10. Choi YS, Lee MY, David AE, Park YS. Nanoparticles for gene delivery: therapeutic and toxic effects. Mol Cell Toxicol. 2014;10:1-8.

11. Wang LH, Wu T, Wu DC, You YZ. Bioreducible gene delivery vector capable of self-scavenging the intracellular-generated ROS exhibiting high gene transfection. ACS Appl Mater Interfaces. 2016;8:19238-19244.

12. Nitta SK, Numata K. Biopolymer-based nanoparticles for drug/gene delivery and tissue engineering. Int J Mol Sci. 2013;14:1629-1654.

13. Hu J, Zhu M, Liu K, Fan H, Zhao W, Mao Y, Zhang Y. A biodegradable polyethylenimine-based vector modified by trifunctional peptide R18 for enhancing gene transfection efficiency in vivo. PLoS One. 2016;11:e0166673.

14. Abbasi E, Aval SF, Akbarzadeh A, Milani M, Nasrabadi HT, Joo SW, Hanifehpour Y, Nejati-Koshki K, Pashaei-Asl R. Dendrimers: synthesis, applications, and properties. Nanoscale Res Lett. 2014;9:247.

15. Taghavi PAN, Mutlu P, Khodadust R, Gunduz U. Poly amidoamine PAMAM nanoparticles: synthesis and biomedical applications. Hacet J Biol Chem. 2013;41:289-299.

16. Dutta T, Jain NK, McMillan NA, Parekh HS. Dendrimer nanocarriers as versatile vectors in gene delivery. Nanomedicine. 2010;6:25- 
34.

17. Kolhatkar RB, Kitchens KM, Swaan PW, Ghandehari H. Surface acetylation of polyamidoamine (PAMAM) dendrimers decreases cytotoxicity while maintaining membrane permeability. Bioconjug Chem. 2007;18:2054-2060.

18. Li J, Han Y, Lu Y, Song B, Zhao M, Hu H, Chen D. A novel disulfide bond-mediated cleavable RGD-modified PAMAM nanocomplex containing nuclear localization signal HMGB1 for enhancing gene transfection efficiency. Int J Nanomedicine. 2018;13:7135-7153.

19. Li J, Liang H, Liu J, Wang Z. Poly (amidoamine) (PAMAM) dendrimer mediated delivery of drug and pDNA/siRNA for cancer therapy. Int J Pharm. 2018;546:215-225.

20. Lee J, Jung J, Kim YJ, Lee E, Choi JS. Gene delivery of PAMAM dendrimer conjugated with the nuclear localization signal peptide originated from fibroblast growth factor 3. Int J Pharm. 2014;459:1018.

21. Lee J, Lee S, Kwon YE, Kim YJ, Choi JS. Gene delivery by PAMAM dendrimer conjugated with the nuclear localization signal peptide derived from influenza B virus nucleoprotein. Macromol Res. 2019;27:360-368.

22. Rollano Peñaloza OM, Lewandowska M, Stetefeld J, Ossysek K, Madej M, Bereta J, Sobczak M, Shojaei S, Ghavami S, Łos MJ. Apoptins: selective anticancer agents. Trends Mol Med. 2014;20:519528.

23. Noteborn MH, van der Eb AJ. Apoptin-induced apoptosis: potential for antitumor therapy. Drug Resist Updat. 1998;1:99-103.

24. Maddika S, Booy EP, Johar D, Gibson SB, Ghavami S, Los M. Cancer-specific toxicity of apoptin is independent of death receptors but involves the loss of mitochondrial membrane potential and the release of mitochondrial cell-death mediators by a Nur77-dependent pathway. J Cell Sci. 2005;118(Pt 19):4485-4493.

25. Hou Z, Mao J, Lu Y, Li L. rApoptin induces apoptosis in human breast cancer cells via phosphorylation of Nur77 and Akt. Biochem
Biophys Res Commun. 2018;498:221-227.

26. An S, Nam K, Choi S, Bai CZ, Lee Y, Park JS. Nonviral gene therapy in vivo with PAM-RG4/apoptin as a potential brain tumor therapeutic. Int J Nanomedicine. 2013;8:821-834.

27. Bae Y, Green ES, Kim GY, Song SJ, Mun JY, Lee S, Park JI, Park JS, Ko KS, Han J, Choi JS. Dipeptide-functionalized polyamidoamine dendrimer-mediated apoptin gene delivery facilitates apoptosis of human primary glioma cells. Int J Pharm. 2016;515:186-200.

28. Bae Y, Jung MK, Song SJ, Green ES, Lee S, Park HS, Jeong SH, Han J, Mun JY, Ko KS, Choi JS. Functional nanosome for enhanced mitochondria-targeted gene delivery and expression. Mitochondrion. 2017;37:27-40.

29. Holder AL, Goth-Goldstein R, Lucas D, Koshland CP. Particleinduced artifacts in the MTT and LDH viability assays. Chem Res Toxicol. 2012;25:1885-1892.

30. Liu BR, Lo SY, Liu CC, Chyan CL, Huang YW, Aronstam RS, Lee HJ. Endocytic trafficking of nanoparticles delivered by cellpenetrating peptides comprised of nona-arginine and a penetration accelerating sequence. PLoS One. 2013;8:e67100.

31. Elefantova K, Lakatos B, Kubickova J, Sulova Z, Breier A. Detection of the mitochondrial membrane potential by the cationic dye JC- 1 in L1210 cells with massive overexpression of the plasma membrane ABCB1 drug transporter. Int J Mol Sci. 2018;19:1985.

32. Dubey A, Goswami M, Yadav K, Chaudhary D. Oxidative stress and nano-toxicity induced by $\mathrm{TiO} 2$ and $\mathrm{ZnO}$ on WAG cell line. PLoS One. 2015;10:e0127493.

33. Uram , Szuster M, Gargasz K, Filipowicz A, Wałajtys-Rode E, Wołowiec S. In vitro cytotoxicity of the ternary PAMAM G3-pyridoxal-biotin bioconjugate. Int J Nanomedicine. 2013;8:4707-4720.

34. Martin ME, Rice KG. Peptide-guided gene delivery. AAPS J. 2007;9:E18-E29.

35. Al-Dosari MS, Gao X. Nonviral gene delivery: principle, limitations, and recent progress. AAPS J. 2009;11:671-681. 